\title{
1 Household cleaning and poor asthma control among elderly women
}

3 Orianne Dumas, $\mathrm{PhD}^{1}$, Annabelle Bédard, $\mathrm{PhD}^{1}$, Matthieu Marbac, $\mathrm{PhD}^{2}$, Mohammed Sedki, $4 \mathrm{PhD}^{3}$, Sofia Temam, $\mathrm{PhD}^{1,4}$, Sébastien Chanoine, $\mathrm{PhD}^{5}$, Gianluca Severi, $\mathrm{PhD}^{6}$, Marie-

5 Christine Boutron-Ruault, $\mathrm{MD}, \mathrm{PhD}^{6}$, Judith Garcia-Aymerich, $\mathrm{MD}, \mathrm{PhD}^{7,8,9}$, Valérie Siroux, $6 \quad \mathrm{PhD}^{5}$, Raphaëlle Varraso, $\mathrm{PhD}^{1}$, Nicole Le Moual, $\mathrm{PhD}^{1}$

1. Université Paris-Saclay, UVSQ, Univ. Paris-Sud, Inserm, Équipe d'Épidémiologie 9 respiratoire intégrative, CESP, 94807, Villejuif, France

2. CREST, Ensai, Campus de KerLan, Bruz, France

3. Université Paris-Saclay, UVSQ, Univ. Paris-Sud, Inserm, Pôle méthodologies et statistique, CESP, 94807, Villejuif, France

4. MGEN Foundation for Public Health (FESP-MGEN), 75748, Paris, France

5. IAB, Team of Environmental Epidemiology Applied to Reproduction and Respiratory Health, INSERM U1209, University of Grenoble-Alpes, CHU de Grenoble, Grenoble, France 6. Université Paris-Saclay, UVSQ, Inserm, CESP, Equipe "Exposome, Hérédité, Cancer et Santé", 94805, Villejuif, France

7. ISGlobal, Barcelona, Spain

8. Universitat Pompeu Fabra (UPF), Barcelona, Spain

9. CIBER Epidemiología y Salud Pública (CIBERESP), Madrid, Spain

\section{Correspondence}

Marie-Christine Boutron-Ruault

Inserm U 1018 / CESP, Centre for Research in Epidemiology and Population Health, Exposome and Heredity Team, Espace Maurice Tubiana, Gustave Roussy, 114 rue Edouard Vaillant 
Telephone number: $+33(0) 142116466$.

E-mail address: marie-christine.boutron@gustaveroussy.fr

\section{$30 \quad$ Funding}

31 This work was supported by the Institut pour la Recherche en Santé Publique (IRESP), and of 32 the joint help of Direction Générale de la Santé (DGS), the Mission recherche de la Direction 33 de la Recherche, des Etudes, de l'Evaluation et des Statistiques (Mire-DREES), the Caisse 34 nationale d'assurance maladie des travailleurs salariés (CNAMTS), Régime Social des 35 Indépendants (RSI) \& Caisse nationale de solidarité pour l'autonomie (CNSA). The E3N-E4N 36 cohort is supported by the Mutuelle Générale de l'Education Nationale (MGEN); the French 37 League against Cancer (LNCC); Gustave Roussy; and the French Research Agency (ANR grant, ANR-10-COHO-0006). ISGlobal acknowledges support from the Spanish Ministry of

Science and Innovation through the "Centro de Excelencia Severo Ochoa 2019-2023” Program 40 (CEX2018-000806-S), and support from the Generalitat de Catalunya through the CERCA 41 Program.

42

43

44

\section{Competing interests}

The authors declare they have no actual or potential competing interests.

Word count: 2944 
Abstract

Background. Asthma control is suboptimal in nearly half of adults with asthma. Household exposure to disinfectants and cleaning products (DCP) has been associated with adverse respiratory effects, but data on their association with asthma control are scant.

Objectives. To investigate the association between household use of DCP and asthma control in a large cohort of French elderly women.

Methods. We used data from a case-control study on asthma (2011-2013) nested in the E3N cohort. Among 3,023 women with current asthma, asthma control was defined by the Asthma Control Test (ACT). We used a standardized questionnaire to assess the frequency of cleaning tasks and DCP use. We also identified household cleaning patterns using a clustering approach. Associations between DCP and ACT were adjusted for age, smoking status, body mass index and education.

Results. Data on ACT and DCP use were available for 2,223 women ( $70 \pm 6$ years old). Asthma was controlled $(\mathrm{ACT}=25)$, partly controlled $(\mathrm{ACT}=20-24)$ and poorly controlled $(\mathrm{ACT} \leq 19)$ in $29 \%, 46 \%$ and $25 \%$ of the participants, respectively. Weekly use of sprays and chemicals were associated with poorly controlled asthma (odds ratio [95\%CI]: 1 spray: 1.31 [0.94-1.84], $\geq 2$ sprays: 1.65 [1.07-2.53], P-trend: 0.01; 1 chemical: 1.24 [0.94-1.64], $\geq 2$ chemicals: 1.47 [1.032.09], P-trend: 0.02). Risk for poor asthma control increased with the patterns "very frequent use of products" (1.74 [1.13-2.70]) and "infrequent cleaning tasks and intermediate use of products" (1.62 [1.05-2.51]).

Conclusion. Regular use of DCP may contribute to poor asthma control in elderly women. Limiting their use may help improve asthma management.

\section{Abstract word count: 250}




\section{$75 \quad$ Highlights}

\section{What is already known about this topic?}

Although avoidance of environmental triggers is recommended in asthma management, environmental determinants of poor asthma control are insufficiently known. Cleaning products may have adverse respiratory effects, but data on their association with asthma control are scant.

\section{What does this article add to our knowledge?}

In this study of 2,223 elderly women with asthma, weekly use of sprays or chemicals for home cleaning, and frequent use of multiple disinfectants and cleaning products, were associated with poor asthma control.

\section{How does this study impact current management guidelines?}

Limiting the use of disinfectants and cleaning products may help improve improving asthma control in adult patients. Given the ubiquitous use of these products, our results may have important impact in asthma management.

Key words

Asthma, Asthma control, Cleaning products, Disinfectants, Environmental exposures, Household exposure, Chemicals, Sprays, Women

Abbreviations:

4 ACT: asthma control test BMI: body masse index

CI: confidence interval

DCP: disinfectants and cleaning products

E3N: Etude Epidémiologique auprès des femmes de la Mutuelle Générale de l'Education

9 Nationale

0 EGEA: Epidemiological study on the Genetics and Environment of Asthma 
101 OR: odds ratio

102 


\section{Introduction}

The primary goal of asthma management is to achieve and maintain the control of the

105 disease, through the control of the environment and optimal asthma treatment. ${ }^{1,2}$ However, 106 asthma control may be suboptimal in 40-50\% of adults with asthma, with even higher rates

107 among women. ${ }^{3,4}$ In elderly patients with asthma, the disease may be more difficult to control 108 because of comorbidities, aging of the lungs and the immune system, and potentially low treatment adherence. ${ }^{5,6}$ Uncontrolled asthma is associated with a substantial economic and health burden, which is largely preventable. ${ }^{7}$ Although avoidance of environmental triggers is

111 strongly recommended in asthma management guidelines, ${ }^{8}$ environmental determinants of poor 112 asthma control are insufficiently known. ${ }^{2}$

113 Concerns regarding the health effects of chemical exposures from consumer products 114 used in everyday life such as disinfectants and cleaning products (DCP) are growing. ${ }^{9-11}$ DCP 115 have been identified as an important source of volatile organic compounds emission and poor 116 air quality. ${ }^{12,13}$ Respiratory health hazard associated with DCP exposures are increasingly 117 recognized, especially among women who are more exposed than men. ${ }^{14,15}$ Associations with 118 respiratory disorders such as asthma have first been evidenced in occupational health studies, 119 mainly among cleaners or healthcare workers. ${ }^{15-18}$ An increasing number of studies suggest that 120 respiratory effects of DCP are not restricted to populations with high exposure level at work,

121 but are also observed in relation to common household exposures. ${ }^{14,19,20}$ Use of DCP at home, 122 in particular cleaning sprays and irritant products, has been associated with asthma 123 incidence, ${ }^{21,22}$ current asthma, or asthma symptoms, ${ }^{23-25}$ and more recently with lung function 124 decline. ${ }^{19}$ To our knowledge, only one study examined the association between DCP exposure 125 at home and asthma control. ${ }^{24}$ In this French cohort, the use of at least two types of cleaning 126 sprays at home was associated with poorly controlled asthma in middle-aged women. 
128 of specific tasks and chemicals that put subjects at risk is needed to establish targeted strategies to improve asthma control. Household cleaning implies various tasks and the possibility of

130 using many chemicals, which makes challenging to disentangle their individual effects. Several

131 approaches can be used. The "a priori" approach classifies DCP exposures based on hypotheses

132 regarding their potential health effects, such as respiratory effects associated with product spraying ${ }^{24}$ or with the use of specific irritant chemicals (e.g., bleach). ${ }^{26}$ Alternatively, data-

134 driven approaches such as clustering models have been proposed to identify exposure patterns,

135 taking into account the multiplicity and correlations of exposures. ${ }^{17,27}$ Fitting a clustering model

136 on a large subsample of elderly women from the French E3N study (Etude Epidémiologique

137 auprès des femmes de la Mutuelle Générale de l'Education Nationale), based on 24 questions

138 on cleaning tasks and products, we recently identified seven household cleaning patterns. ${ }^{27}$

139 In the current study, we aimed to investigate the association of DCP use and household 140 cleaning patterns with asthma control among elderly women from the E3N study. 
Population

The E3N study, initiated in 1990, is a prospective cohort among women affiliated to the

147 Mutuelle Générale de l'Education Nationale, a French national health insurance plan covering 148 mostly teachers. ${ }^{28}$ A total of 98,997 women aged $40-65$ years were included at baseline and 149 have been followed up approximately every 2 years since. The current analysis uses data from 150 a nested case-control study on asthma (Asthma-E3N) conducted in 2011-2013. ${ }^{23,29,30}$ A total of

1517,100 women with asthma (positive answer to the question "Have you ever had an asthma 152 attack?" in at least one questionnaire since 1990) and 14,200 age-matched women without 153 asthma were invited to complete a postal questionnaire regarding respiratory health and environmental exposures. Questionnaires were returned by 19,404 participants $(92 \%)$. The study protocol was approved by the French Institutional Ethics Committee, and all participants 156 provided their written informed consents.

\section{Asthma control}

Among women with current asthma (ever asthma, and occurrence of asthma attacks, asthma treatment, or asthma symptoms in the past 12 months), asthma control was defined using the Asthma Control Test (ACT). The ACT score (range 5-25) is based on five questions

162 on activity limitations, frequency of symptoms, and frequency of use of quick-relief medication

163 in the past 4 weeks. ${ }^{31}$ In main analyses, asthma control was classified into three categories based 164 on the ACT score (25: controlled; 20-24: partly controlled; $\leqslant 19$ : poorly controlled). ${ }^{18,32} \mathrm{We}$ 165 conducted secondary analyses using the more common ACT two-category classification (20$16625 ; \leqslant 19) .{ }^{31}$ 
The nested case-control study included a detailed standardized questionnaire ${ }^{21,24}$ on the questions), use of specific cleaning products (7 questions), and use of different types of sprays

172 (7 questions) at home.

Weekly use of spray was classified as none, one type of spray, or $\geq 2$ types of sprays, based on the seven questions regarding type of spray used (for furniture, windows/mirrors, floor, degreasing/oven, air-refreshing, pesticide, and other). Similarly, weekly use of chemicals was classified as none, one type of chemical, or $\geq 2$ types of chemicals, based on the four

177 questions regarding type of chemical used (ammonia, acids, stain removers/solvents, bleach).

178 Weekly use of each of the seven types of spray and four chemicals was also examined individually. In all analyses, we used as reference category (unexposed) participants reporting no weekly use of any of the seven types of spray and four chemicals, to avoid including in the reference category participants with any potentially hazardous exposure. ${ }^{18,33}$

To identify household cleaning patterns, we used a mixture model of dependency

183 blocks, as described in detail elsewhere. ${ }^{27}$ Briefly, this approach extends the standard latent class mode ${ }^{34}$ to the case where within-class dependencies occur. Considering the within-class dependency was important because of the high dependencies between the use of different DCP, even within an homogenous subpopulation. The model identified seven household cleaning

187 patterns which differed on the frequency of cleaning tasks and use of specific products.

Statistical analyses

Associations between exposure to DCP and asthma control (controlled, partly controlled, poorly controlled) were evaluated by multinomial logistic regression models.

192 Analyses were adjusted for age, smoking status (nonsmoker, ex-smoker, or current smoker), 
193 body mass index (BMI: $<20.0,20.0-24.9,25.0-29.9$, and $\geq 30.0)$, and education level $(<$ high

194 school diploma, high school to 2-level university, $\geq 3$-level university). A two-sided $p<0.05$

195 was considered statistically significant. Analyses were run using SAS version 9.3 (SAS

196 Institute, Cary, NC, USA).

197 As household help (positive answer to the question "does someone help you for

198 household cleaning, e.g., husband, household employee, or family members?") has previously

199 been suggested to induce misclassification in assessment of exposure to DCP, ${ }^{23}$ sensitivity

200 analyses restricted to women with no household help were conducted when examining specific

201 products. In another sensitivity analysis, we used multiple imputation to estimate ACT missing

202 values assuming a missing at random pattern, ${ }^{35}$ as in previous analyses in Asthma-E3N ${ }^{30}$ and

203 as detailed in online supplementary material, to evaluate the robustness of our results to missing

204 value issues. Finally, a sensitivity analysis with adjustment for multimorbidity-related

205 medication profiles previously identified using drug administrative databases (see Chanoine et

$206 \mathrm{al}^{36}$ and online supplementary material) was performed, as these profiles were a strong

207 determinant of poor asthma control in this population of elderly women, ${ }^{36}$ and may be related

208 to use of DCP. 


\section{Results}

Among the 7,100 women with ever asthma invited to participate, 6,274 (88\%) returned

213 the questionnaire, of whom 3,023 had current asthma (Figure 1). Women with missing data for

214 all questions on household cleaning $(n=18)$, smoking status $(n=25)$, or asthma control $(n=747)$

215 were excluded. This yielded a population of 2,233 women eligible for analyses. Participants

216 were 69.7 years old on average, $46 \%$ were ex-smokers and $4 \%$ were current smokers, $13 \%$ had

217 a BMI $\geq 30 \mathrm{~kg} / \mathrm{m}^{2}$, and $37 \%$ had a high education level ( $\geq$ 3-level university). Nearly half of

218 the participants (48\%) reported household help. Asthma was controlled in $29 \%$ of the

219 participants, partly controlled in $46 \%$ and poorly controlled in $25 \%$. Women with poorly

220 controlled asthma were older and had lower education level (Table 1). They more often reported 221 household help.

Regarding use of specific DCP, 17\% of the participants used one type of spray weekly, and $9 \%$ used $\geq 2$ types of spray; $35 \%$ used one type of chemical, and $15 \%$ used $\geq 2$ types of chemicals. The most frequently used sprays were air-refreshing sprays (weekly use: 14\%) and windows/mirrors sprays ( $8 \%)$, and the most frequently used chemicals were bleach $(39 \%)$ and acids (19\%). The seven household cleaning patterns identified by a clustering approach are described in Table 2. Household cleaning tasks, and use of sprays and chemicals according to household cleaning patterns are described in online supplementary Table E1. Cleaning patterns were ordered by frequency of general cleaning tasks, which did not always correspond to the

230 frequency of product use. For instance, while women in the "medium cleaning" pattern reported 231 less frequent cleaning tasks (weekly household cleaning: 29\%) than women in the "frequent general cleaning" pattern (85\%), they reported using more sprays (weekly use of $\geq 2$ types of spray: $18 \% v s .2 \%$ ) and chemicals (weekly use of $\geq 2$ types of chemicals: $19 \%$ vs. $9 \%$ ) 
$1.84 ; \geq 2$ types of spray: $1.65,1.07-2.53$; P-trend: 0.01 ). Similarly, weekly use of chemicals was

237

238

239

240

241

242

243

244 associated with poorly controlled asthma (1 type of chemical: OR: $1.24,95 \% \mathrm{CI}: 0.94-1.64 ; \geq 2$ types of chemical: 1.47, 1.03-2.09; P-trend: 0.02). Associations were more pronounced when analyses were restricted to women without household help. Results were similar when ACT was studied in two categories ( $\leqslant 19$ vs. $20-25$, table E2). When examining specific DCP individually, associations with poor asthma control were observed or suggested for several products (online supplementary Table E3 \& E4). Weekly use of windows/mirror sprays (1.91, 1.23-2.97), air-refreshing sprays $(1.54,1.07-2.22)$, acids $(1.45,1.04-2.02)$, stain removers/ solvents $(1.89,1.13-3.17)$, and bleach $(1.34,1.03-1.74)$ were associated with poorly controlled asthma in all women. When analyses were restricted to women without household help, associations of weekly use of furniture sprays $(2.48,1.22-5.06)$ and other sprays $(5.99,1.56-$ 23.0) and poorly controlled asthma were further observed.

In the multivariable model examining household cleaning patterns (Figure 2), the most common pattern (“frequent general cleaning”) was used as reference group. Compared to this pattern, associations with poorly controlled asthma were observed for the "medium cleaning" pattern (Odds Ratio (OR): 1.62, 95\% Confidence Interval [CI]: 1.05-2.51), and for the "very frequent use of products" pattern (OR: 1.74, 95\%CI: 1.13-2.70).

After multiple imputation, 747 additional women with missing values for ACT score were included in the analyses. Association between DCP exposures and asthma control were similar in the imputed dataset (online supplementary table E5). Association were also similar in sensitivity analysis with adjustment for multimorbidity-related medication profiles (online supplementary table E6). 
Discussion

In this study of 2,223 elderly women with asthma, self-reported weekly use of at least 2 types of sprays or at least 2 types of chemicals for home cleaning was associated with poor asthma control. In addition, a household cleaning pattern with very frequent use of multiple disinfectants and cleaning products was associated with poor asthma control.

Our results are consistent and extend results from the only other study that examined the association between use of cleaning sprays at home and asthma control. In this previous study among 683 French women (244 with asthma) from the Epidemiological study on the Genetics and Environment of Asthma (EGEA), weekly use of $\geq 2$ types of sprays was associated with poorly controlled asthma. ${ }^{24}$ In the current study, we found that this association was not restricted to cleaning sprays but was also observed for the use of chemicals. In EGEA, use of bleach for home cleaning was not associated with poor asthma control ${ }^{26}$. However, analyses were limited by a small sample size, which also limited the investigation of exposure to multiple chemicals. The current results are also in accordance with findings from a few occupational studies reporting an association between occupational exposure to DCP and poor asthma control. ${ }^{18,37,38}$

We attempted to disentangle the roles of specific products using several approaches.

277 First, we compared contrasted groups of individuals based on a priori hypotheses regarding the 278 effect of some products (e.g., sprays vs. chemicals, individual products). However, this 279 approach has limitations as in the "real world", products are generally not used in isolation; we 280 thus could not build fully contrasted groups defined by the use of only one product or one type 281 of products. Second, we used clustering to identify household cleaning patterns, grouping 282 participants with similar cleaning habits, and reflecting "real world" DCP use. The resulting 283 patterns were distinguished by their general frequency of cleaning tasks and product use, with 284 a gradient from very low to very high frequencies for the use of multiple products. However, 
no profile characterized by the use of one or a few specific products emerged. This limited our ability to identify specific patterns of use associated with poor asthma control, beside the use of multiple products. Despite these limitations, our results, in accordance with several previous studies at the workplace, ${ }^{16-18}$ suggest that adverse respiratory effects are not imputable to a single product, but may result from the frequent use of a multitude of products. Moreover, there is a biological plausibility for an effect on the airways of all the specific products investigated. The active compounds of many disinfectants (e.g., bleach, acids) have been described as airway

292 irritants..$^{39,40}$ Inhalation of irritants is thought to cause airway damage, oxidative stress and neutrophilic inflammation. ${ }^{26,41,42}$ A direct disruptive effect of exposure to laundry detergents on

294 the epithelial barrier integrity has recently been suggested, and may be relevant for other 295 household cleaning products. ${ }^{11,43,44}$ DCP also commonly contain skin allergens such as 296 perfumes (e.g., terpenes). ${ }^{12,40,45}$ Finally, product spraying is likely to increase exposure by 297 inhalation. A recent study examining the potential for airway exposure when using cleaning 298 spray showed that the particles generated were in a size range relevant for both nasal and 299 alveolar deposition. ${ }^{46}$ To improve knowledge regarding agents causing respiratory hazards, the 300 use of novel exposure assessment methods, such as a Smartphone application to scan the 301 barcodes of DCP and the development of databases listing all ingredients of DCP may be useful in future studies. ${ }^{47}$ Major strengths of our study include the large population size, the high response rate 304 and the use of standardized and validated definitions to evaluate asthma and asthma control.

305 Our population only included elderly women with relatively high education levels and may not 306 be generalizable to different populations. However, similar results have been observed in a 307 cohort of middle-aged women, ${ }^{24}$ Although no study has specifically examined the impact of 308 DCP exposures on asthma control in men, associations between DCP and asthma have been 309 reported in populations of both men and women..$^{21,22}$ 
We used a standardized questionnaire to evaluate DCP exposures, as in previous

311 studies. ${ }^{21,22,24}$ Use of DCP was self-reported, which may raise concerns regarding a potential

312 differential misclassification bias (recall bias). Such a bias would occur if women with poor

313 asthma control tended either to overestimate or to recall more precisely their use of DCP

314 compared to women with controlled asthma. However, we assume that this bias is less

315 pronounced than when comparing asthmatics to non-asthmatics. Another potential bias would

316 be reverse causation, which would occur if women with poor asthma control were seeking to

317 live in a cleaner environment (e.g., to avoid dust or mold exposures), which would involve more

318 frequent cleaning tasks. Although these biases cannot be completely ruled out, they are unlikely

319 for several reasons. First, when examining household cleaning patterns, two patterns could

320 either result from a recall bias or reflect a behavior of seeking a clean environment: "very

321 frequent use of products" which involved very frequent use of chemicals and cleaning sprays,

322 and "very frequent general cleaning" which involved very frequent general cleaning tasks (e.g.,

323 dusting/hoovering) but with moderate use of products. However, only the pattern "very frequent

324 use of products" was associated with poor asthma control. Second, our results are consistent

325 with studies on occupational exposure, in which exposures were evaluated by job- or job-task-

326 exposure matrices, ${ }^{18,37}$ less prone to recall bias, and where the frequency of cleaning tasks is

327 driven by workplace requirements rather than by individual behaviors.

328 In analyses of household cleaning patterns, poor asthma control was associated not only

329 with the "very frequent use of cleaning products" pattern, but also with a pattern of infrequent

330 cleaning tasks and intermediate use of products. We also observed that women with poor

331 asthma control more frequently had household help. These results may reflect a "healthy home

332 cleaning effect", as suggested in previous studies. ${ }^{22,24}$ Such effect may occur if women with

333 respiratory symptoms or poor asthma control avoid or reduce their use of DCP. ${ }^{22,24}$ Similarly

334 to the healthy worker effect in occupational studies, this bias is difficult to control in cross- 
335 sectional studies. ${ }^{48}$ No question on avoidance of use of DCP was available in the current study.

336 The result of such as bias would be a general underestimation of the associations observed in

337 our study. Despite this potential underestimation, we observed relatively elevated ORs (range

338 1.3-2.0) for the association between weekly use of several specific DCP and poorly controlled 339 asthma.

340 In conclusion, we found that the weekly use of several types of DCP for home cleaning 341 was associated with poor asthma control in elderly women. While more research is needed to 342 precisely identify causative agents and mechanisms, reduction in exposure and development of 343 safer methods/products for home cleaning is recommended. Clinicians should be aware of this

344 environmental risk factor for poor asthma control and integrate it in asthma management 345 strategies. ${ }^{8}$ Given the ubiquitous use of disinfectants and cleaning products, our results may 346 have important impact in improving asthma control in adult patients.

\section{$350 \quad$ Acknowledgments}

351 The authors would like to thank the E3N team and especially M Fangon, M Niravong, LA 352 Hoang, M Valdenaire, S Eltaief, R Gomes, F Wilm, C Kernaleguen, W Tello, C Laplanche, P 353 Gerbouin-Rérolle, R Chaït, G Esselma, and F Clavel-Chapelon (Inserm U1018 CESP, Villejuif, 354 France) for the implementation and management of the E3N study. They are indebted to all 355 participants, without whom the study would not have been possible, for their high involvement 356 in the E3N study. 


\section{References}

1. Global Initiative for Asthma. Global Strategy for Asthma Management and Prevention, 2020. Available from: www.ginasthma.org.

2. Schatz M. Predictors of asthma control: what can we modify? Curr Opin Allergy Clin Immunol. 2012;12:263-8.

3. Braido F, Brusselle G, Guastalla D, Ingrassia E, Nicolini G, Price D, et al. Determinants and impact of suboptimal asthma control in Europe: The International Cross-Sectionnal And Longitudinal Assessment On Asthma Control (LIAISON) study. Respir Res. 2016;17:51.

4. Fuhlbrigge A, Reed ML, Stempel DA, Ortega HO, Fanning K, Stanford RH. The status of asthma control in the U.S. adult population. Allergy Asthma Proc. 2014;30:529-33.

5. Ban GY, Trinh THK, Ye YM, Park HS. Predictors of asthma control in elderly patients. Curr Opin Allergy Clin Immunol. 2016;16:237-43.

6. Skloot GS, Busse PJ, Braman SS, Kovacs EJ, Dixon AE, Vaz Fragoso CA, et al. An official American thoracic society workshop report: Evaluation and management of asthma in the elderly. Ann Am Thorac Soc. 2016;13:2064-77.

7. Yaghoubi M, Adibi A, Safari A, FitzGerald JM, Sadatsafavi M. The projected economic and health burden of uncontrolled asthma in the United States. Am J Respir Crit Care Med. 2019;200:1102-12.

8. Beasley R, Braithwaite I, Semprini A, Kearns C, Weatherall M, Pavord ID. Optimal Asthma Control: Time for a New Target. Am J Respir Crit Care Med. 2020;201:1480 7.

9. Gabb HA, Blake C. An Informatics Approach to Evaluating Combined Chemical Exposures from Consumer Products: A Case Study of Asthma-Associated and Potential Endocrine Disruptors. Environ Health Perspect. 2016;124:1155-65.

10. Zota AR, Singla V, Adamkiewicz G, Mitro SD, Dodson RE. Reducing chemical exposures at home: Opportunities for action. J Epidemiol Community Health. 2017;71:937-40.

11. Celebi Sözener Z, Cevhertas L, Nadeau K, Akdis M, Akdis CA. Environmental factors in epithelial barrier dysfunction. J Allergy Clin Immunol. 2020;145:1517-28.

12. Nematollahi N, Kolev SD, Steinemann A. Volatile chemical emissions from 134 common consumer products. Air Qual Atmos Heal. 2019;

13. McDonald BC, de Gouw JA, Gilman JB, Jathar SH, Akherati A, Cappa CD, et al. Volatile chemical products emerging as largest petrochemical source of urban organic emissions. Science (80- ). 2018;359:760-4.

14. Dumas O, Le Moual N. Damaging effects of household cleaning products on the lungs. Expert Rev Respir Med. 2020;14:1-4.

15. Folletti I, Siracusa A, Paolocci G. Update on asthma and cleaning agents. Curr Opin Allergy Clin Immunol. 2017;17:90-5.

16. Brooks C, Slater T, Corbin M, McLean D, Tua Firestone R, Zock J, et al. Respiratory health in professional cleaners: symptoms, lung function, and risk factors. Clin Exp Allergy. 2020;50:567-76.

17. Su FC, Friesen MC, Humann M, Stefaniak AB, Stanton ML, Liang X, et al. Clustering asthma symptoms and cleaning and disinfecting activities and evaluating their associations among healthcare workers. Int J Hyg Environ Health. 2019;222:873-83.

18. Dumas O, Wiley AS, Quinot C, Varraso R, Zock J-P, Henneberger PK, et al. Occupational exposure to disinfectants and asthma control in US nurses. Eur Respir J. 2017;50:pii: 1700237.

19. Svanes Ø, Bertelsen RJ, Lygre S, Carsin A, Antó J, Forsberg B, et al. Cleaning at 
Home and at Work in Relation to Lung Function Decline and Airway Obstruction. Am J Respir Crit Care Med. 2018;197:1157-63.

20. Liu X, Lao X, Wong C, Tan L, Zhang Z, Wong T, et al. Frequent use of household cleaning products is associated with rhinitis in Chinese children. J Allergy Clin Immunol. 2016;138:754-60.

21. Zock JP, Plana E, Jarvis D, Antó JM, Kromhout H, Kennedy SM, et al. The use of household cleaning sprays and adult asthma: an international longitudinal study. Am J Respir Crit Care Med. 2007;176:735-41.

22. Weinmann T, Gerlich J, Heinrich S, Nowak D, Von Mutius E, Vogelberg C, et al. Association of household cleaning agents and disinfectants with asthma in young German adults. Occup Environ Med. 2017;74:684-90.

23. Bédard A, Varraso R, Sanchez M, Clavel-Chapelon F, Zock JP, Kauffmann F, et al. Cleaning sprays, household help and asthma among elderly women. Respir Med. 2014;108:171-80.

24. Le Moual N, Varraso R, Siroux V, Dumas O, Nadif R, Pin I, et al. Domestic use of cleaning sprays and asthma activity in females. Eur Respir J. 2012;40:1381-9.

25. Lemire P, Dumas O, Chanoine S, Temam S, Severi G, Boutron-Ruault MC, et al. Domestic exposure to irritant cleaning agents and asthma in women. Environ Int. 2020;144:106017.

26. Matulonga B, Rava M, Siroux V, Bernard A, Dumas O, Pin I, et al. Women using bleach for home cleaning are at increased risk of non-allergic asthma. Respir Med. 2016;117:264-71.

27. Marbac M, Sedki M, Boutron-Ruault MC, Dumas O. Patterns of cleaning product exposures using a novel clustering approach for data with correlated variables. Ann Epidemiol. 2018;28:563-569.e6.

28. Clavel-Chapelon F. Cohort Profile: The French E3N Cohort Study. Int J Epidemiol. 2015;44:801-9.

29. Sanchez M, Varraso R, Bousquet J, Clavel-Chapelon F, Pison C, Kauffmann F, et al. Perceived 10-year change in respiratory health: Reliability and predictive ability. Respir Med. 2015;109:188-99.

30. Temam S, Chanoine S, Bédard A, Dumas O, Sanchez M, Boutron-Ruault MC, et al. Low socioeconomic position and neighborhood deprivation are associated with uncontrolled asthma in elderly. Respir Med. 2019;158:70-7.

31. Schatz M, Sorkness CA, Li JT, Marcus P, Murray JJ, Nathan RA, et al. Asthma Control Test: Reliability, validity, and responsiveness in patients not previously followed by asthma specialists. J Allergy Clin Immunol. 2006;117:549-56.

32. Corrado A, Renda T, Polese G, Rossi A. Assessment of asthma control: The SERENA study. Respir Med. 2013;107:1659-66.

33. Zock JP, Cavalle N, Kromhout H, Kennedy SM, Sunyer J, Jaen A, et al. Evaluation of specific occupational asthma risks in a community-based study with special reference to single and multiple exposures. J Expo Anal Env Epidemiol. 2004;14:397-403.

34. Goodman LA. Exploratory latent structure analysis using both identifiable and unidentifiable models. Biometrika. 1974;61:215-31.

35. Sterne JAC, White IR, Carlin JB, Spratt M, Royston P, Kenward MG, et al. Multiple imputation for missing data in epidemiological and clinical research: Potential and pitfalls. BMJ. 2009;339:157-60.

36. Chanoine S, Sanchez M, Pin I, Temam S, Moual N Le, Fournier A, et al. Multimorbidity medications and poor asthma prognosis. Eur Respir J. 2018;51:1702114.

37. Le Moual N, Carsin A-E, Siroux V, Radon K, Norback D, Torén K, et al. Occupational 
exposures and uncontrolled adult-onset asthma in the European Community Respiratory Health Survey II. Eur Respir J. 2014;43:374-86.

38. Dumas O, Siroux V, Luu F, Nadif R, Zock J-P, Kauffmann F, et al. Cleaning and asthma characteristics in women. Am J Ind Med. 2014;57:303-11.

39. Baur X. A compendium of causative agents of occupational asthma. J Occup Med Toxicol. 2013;8:15.

40. Clausen PA, Frederiksen M, Sejbæk CS, Sørli JB, Hougaard KS, Frydendall KB, et al. Chemicals inhaled from spray cleaning and disinfection products and their respiratory effects. A comprehensive review. Int J Hyg Environ Health. 2020;229:113592.

41. Tarlo SM. Irritant-induced asthma in the workplace. Curr Allergy Asthma Rep. 2014; $14: 406$.

42. Dumas O, Matran R, Zerimech F, Decoster B, Huyvaert H, Ahmed I, et al. Occupational exposures and fluorescent oxidation products in 723 adults of the EGEA study. Eur Respir J. 2015;46:258-61.

43. Wang M, Tan G, Eljaszewicz A, Meng Y, Wawrzyniak P, Acharya S, et al. Laundry detergents and detergent residue after rinsing directly disrupt tight junction barrier integrity in human bronchial epithelial cells. J Allergy Clin Immunol. 2019;143:1892903.

44. Van Den Broucke S, Pollaris L, Vande Velde G, Verbeken E, Nemery B, Vanoirbeek J, et al. Irritant-induced asthma to hypochlorite in mice due to impairment of the airway barrier. Arch Toxicol. 2018;92:1551-61.

45. Wei W, Boumier J, Wyart G, Ramalho O, Mandin C. Cleaning practices and cleaning products in nurseries and schools: to what extent can they impact indoor air quality? Indoor Air. 2016;26:517-25.

46. Lovén K, Isaxon C, Wierzbicka A, Gudmundsson A. Characterization of airborne particles from cleaning sprays and their corresponding respiratory deposition fractions. J Occup Environ Hyg. 2019; 16:656-67.

47. Quinot C, Amsellem-Dubourget S, Temam S, Sevin E, Barreto C, Tackin A, et al. Development of a bar code-based exposure assessment method to evaluate occupational exposure to disinfectants and cleaning products: A pilot study. Occup Environ Med. 2018;75:668-74.

48. Dumas O, Le Moual N, Siroux V, Heederik D, Garcia-Aymerich J, Varraso R, et al. Work related asthma. A causal analysis controlling the healthy worker effect. Occup Env Med. 2013;70:603-10. 
E3N: prospective study among women members of a French health insurance plan

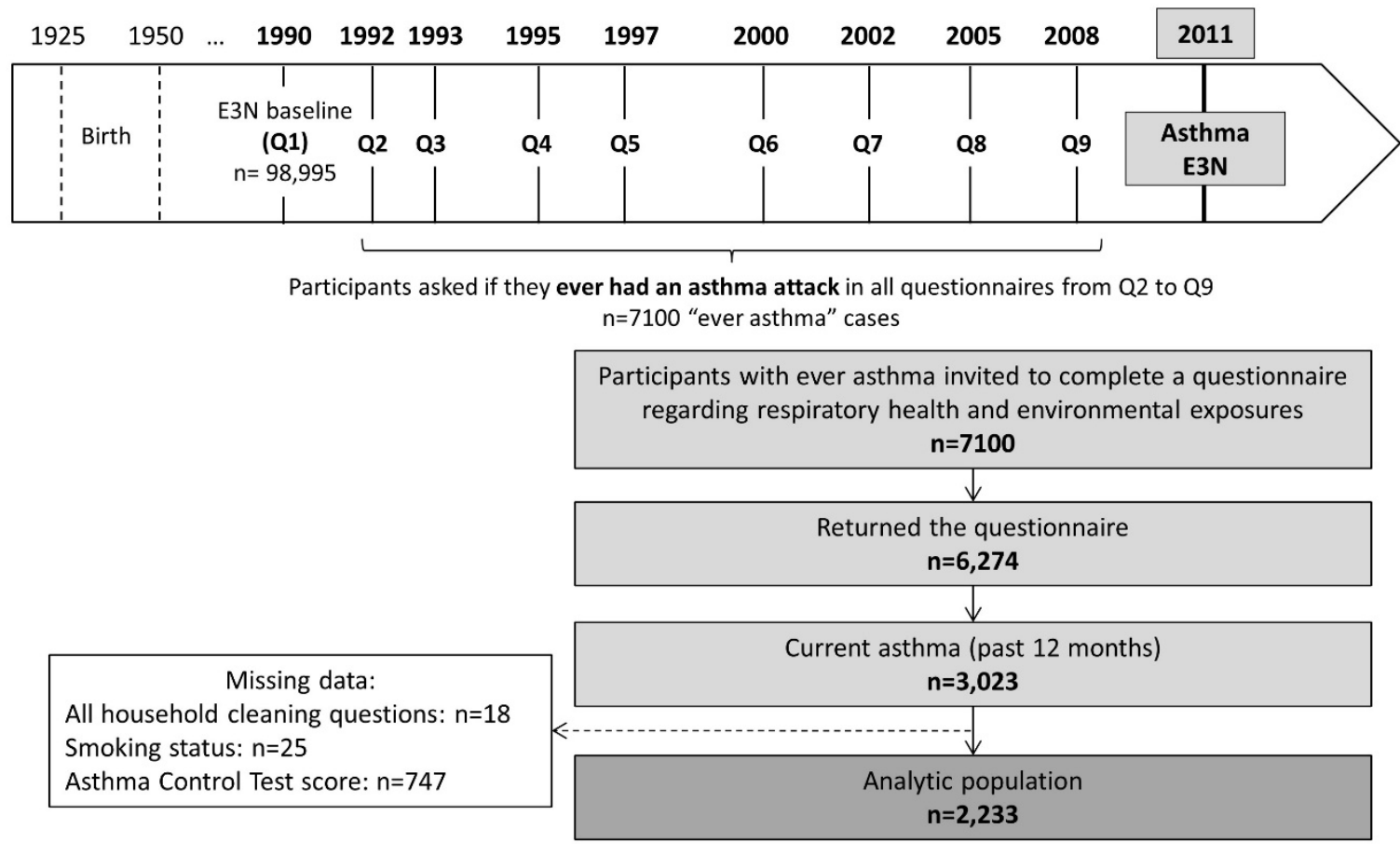

Figure 1. Flow chart of the study population 


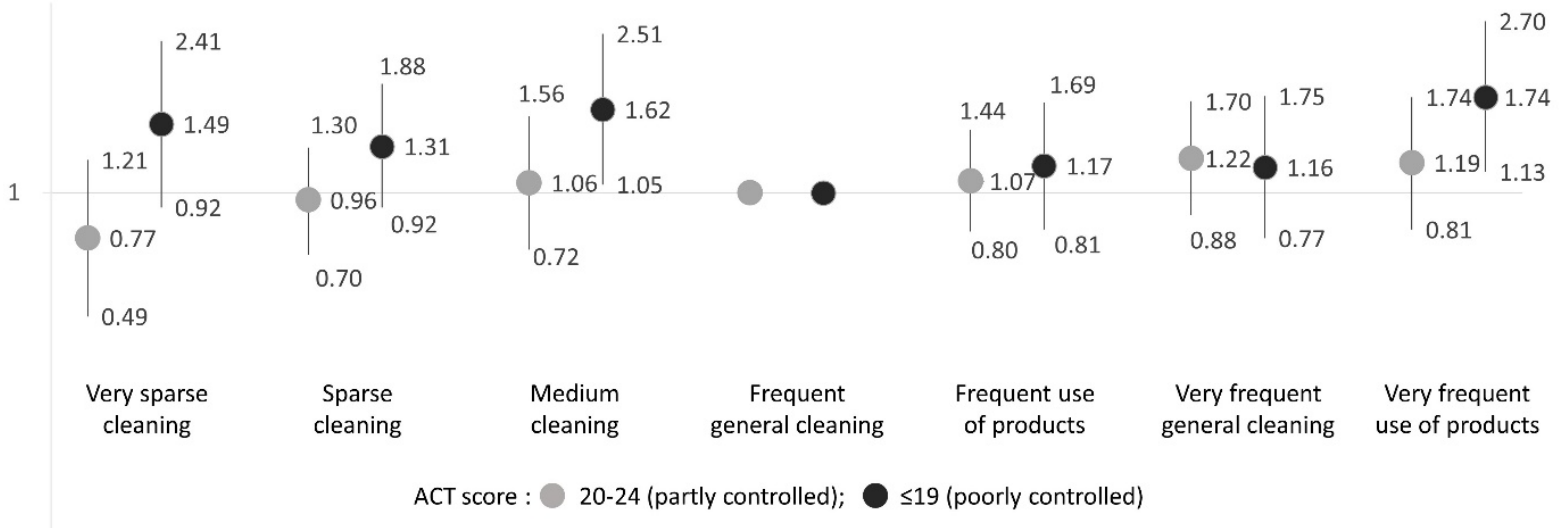

Figure 2. Associations between household cleaning patterns and asthma control.

Results are presented as odds ratios and 95\% confidence intervals for a decrease in Asthma Control Test (ACT) score category (25: controlled [ref.]; 20-24: partly controlled; <19: poorly controlled) adjusted for age, smoking status, body mass index, and education level. The most common pattern ("frequent general cleaning") was used as reference category. 
Table 1. Characteristics of the participants according to asthma control, among 2,233 women with current asthma

\begin{tabular}{|c|c|c|c|c|}
\hline & \multicolumn{3}{|c|}{ Asthma Control Test score } & \multirow[b]{2}{*}{$\mathrm{P}$} \\
\hline & $\begin{array}{c}25 \\
\text { (controlled) }\end{array}$ & $\begin{array}{c}20-24 \\
\text { (partly controlled) }\end{array}$ & $\begin{array}{c}\leq 19 \\
\text { (poorly controlled) }\end{array}$ & \\
\hline $\mathrm{n}(\%)$ & $650(29)$ & $1,024(46)$ & $559(25)$ & \\
\hline Age, m (sd) & $68.6(5.7)$ & $69.4(5.8)$ & $71.4(6.3)$ & $<0.001$ \\
\hline \multicolumn{5}{|l|}{ Smoking status*, \% } \\
\hline Never smoker & 49 & 49 & 53 & 0.38 \\
\hline Ex-smoker & 47 & 47 & 43 & \\
\hline Current smoker & 4 & 4 & 4 & \\
\hline \multicolumn{5}{|l|}{ BMI $\left(\mathrm{kg} / \mathrm{m}^{2}\right), \%$} \\
\hline$<20$ & 11 & 9 & 10 & 0.04 \\
\hline $20-24.9$ & 49 & 49 & 44 & \\
\hline $25-29.9$ & 28 & 31 & 29 & \\
\hline$\geq 30$ & 12 & 11 & 17 & \\
\hline \multicolumn{5}{|l|}{ Education level, \% } \\
\hline$<$ high school diploma & 8 & 9 & 15 & $<0.001$ \\
\hline $\begin{array}{l}\text { High school to 2-level } \\
\text { university }\end{array}$ & 48 & 49 & 50 & \\
\hline$\geq 3$-level university & 40 & 39 & 30 & \\
\hline Missing & 4 & 3 & 5 & \\
\hline Household help, \% & 47 & 46 & 54 & 0.01 \\
\hline
\end{tabular}

BMI - Body Mass Index. 
Table 2. Description of the seven household cleaning patterns identified by a clustering approach, among 2,233 women with asthma

\begin{tabular}{|c|c|c|}
\hline Name & Description & n (\%) \\
\hline Very sparse cleaning & Very infrequent cleaning tasks and use of DCP & $155(7)$ \\
\hline Sparse cleaning & $\begin{array}{l}\text { Infrequent cleaning tasks and very infrequent use of } \\
\text { DCP }\end{array}$ & $376(17)$ \\
\hline Medium cleaning & Infrequent cleaning tasks and intermediate use of DCP & $211(9)$ \\
\hline $\begin{array}{l}\text { Frequent general } \\
\text { cleaning (reference) }\end{array}$ & $\begin{array}{l}\text { High frequency of general cleaning tasks (general } \\
\text { cleaning, dusting/sweeping/hoovering, humid cleaning), } \\
\text { moderate use of general-purpose cleaning products (e.g., } \\
\text { general purpose products, bleach, window/mirror), and } \\
\text { low use of chemicals and sprays }\end{array}$ & $602(27)$ \\
\hline $\begin{array}{l}\text { Frequent use of } \\
\text { products }\end{array}$ & $\begin{array}{l}\text { High frequency of cleaning tasks (general cleaning, } \\
\text { dusting/ sweeping/hoovering, humid cleaning) and use } \\
\text { of DCP (bleach, polishing/waxing, windows/mirrors, } \\
\text { chemicals, sprays) }\end{array}$ & $389(17)$ \\
\hline $\begin{array}{l}\text { Very frequent } \\
\text { general cleaning }\end{array}$ & $\begin{array}{l}\text { Very high frequency of cleaning tasks (general cleaning, } \\
\text { dusting/sweeping/hoovering, humid cleaning), moderate } \\
\text { to high use of general cleaning products, medium use of } \\
\text { chemicals and low use of sprays }\end{array}$ & $285(13)$ \\
\hline $\begin{array}{l}\text { Very frequent use of } \\
\text { products }\end{array}$ & $\begin{array}{l}\text { Very high frequency of cleaning tasks and use of DCP, } \\
\text { especially bleach, chemicals, and sprays. }\end{array}$ & $215(10)$ \\
\hline
\end{tabular}


Table 3. Associations between types of DCP and asthma control

\begin{tabular}{ccccccc}
\hline & \multicolumn{5}{c}{ Asthma Control Test score } \\
\hline & $\begin{array}{c}25 \text { (ref.; } \\
\text { controlled) }\end{array}$ & $\begin{array}{c}20-24 \text { (partly } \\
\text { controlled) }\end{array}$ & $\leq 19$ (poorly controlled) \\
\hline $\mathrm{n}$ & $\%$ & $\mathrm{OR}^{*}$ & $\%$ & $\mathrm{OR}^{*}(95 \% \mathrm{CI})$ & $\%$ & $\mathrm{OR}^{*}(95 \% \mathrm{CI})$ \\
\hline
\end{tabular}

Weekly use of sprays

In all participants

$\begin{array}{cccccccc}\text { No (ref.) } \dagger & 863 & 32 & 1 & 46 & 1 & 22 & 1 \\ 1 \text { type } & 372 & 29 & 1 & 44 & 1.05(0.78-1.40) & 27 & 1.31(0.94-1.84) \\ \geq 2 \text { types } & 202 & 24 & 1 & 45 & 1.29(0.88-1.89) & 31 & \mathbf{1 . 6 5}(\mathbf{1 . 0 7 - 2 . 5 3 )} \\ P \text {-trend } & & & & & 0.24 & & \mathbf{0 . 0 1}\end{array}$

In participants without household help

$\begin{array}{lllllccc}\text { No (ref.) } \dagger & 465 & 34 & 1 & 48 & 1 & 18 & 1 \\ 1 \text { type } & 228 & 30 & 1 & 45 & 1.03(0.70-1.50) & 25 & 1.47(0.93-2.32) \\ \geq 2 \text { types } & 108 & 22 & 1 & 48 & 1.46(0.85-2.49) & 30 & \mathbf{2 . 0 5}(\mathbf{1 . 1 1 - 3 . 8 0}) \\ P \text {-trend } & & & & & 0.24 & & \mathbf{0 . 0 1}\end{array}$

\section{Weekly use of chemicals}

In all participants

\begin{tabular}{|c|c|c|c|c|c|c|c|}
\hline No (ref.) $\dagger$ & 863 & 32 & 1 & 46 & 1 & 22 & 1 \\
\hline 1 type & 733 & 28 & 1 & 47 & $1.15(0.91-1.45)$ & 25 & $1.24(0.94-1.64)$ \\
\hline$\geq 2$ types & 316 & 28 & 1 & 42 & $1.06(0.78-1.45)$ & 30 & $1.47(1.03-2.09)+$ \\
\hline$P$-trend & & & & & 0.48 & & 0.02 \\
\hline
\end{tabular}

In participants without household help

$\begin{array}{lllllccc}\text { No (ref.) } \dagger & 465 & 34 & 1 & 48 & 1 & 18 & 1 \\ 1 \text { type } & 413 & 29 & 1 & 48 & 1.14(0.83-1.55) & 23 & 1.39(0.95-2.04) \\ \geq 2 \text { types } & 189 & 30 & 1 & 42 & 0.97(0.65-1.45) & 28 & 1.59(1.00-2.54) \ddagger \\ P \text {-trend } & & & & & 0.89 & & \mathbf{0 . 0 3}\end{array}$

* OR from multinomial logistic regressions, adjusted for age, smoking status, body mass index, and education level. OR - odds ratio; CI - confidence interval. $\uparrow$ Reference group in all analyses: No weekly use of sprays or chemicals. Results in bold face are statistically significant (comparison with reference group "controlled"). + Statistically significant difference when comparing "poorly controlled" to "partly controlled". 